\title{
One-year Clinically Important Deterioration and Long-Term Clinical Course in Japanese patients with COPD: A Multicenter Observational Cohort Study
}

\author{
Yuki Abe ( $\sim$ abeyuki@pop.med.hokudai.ac.jp) \\ Hokkaido University \\ Masaru Suzuki \\ Hokkaido University: Hokkaido Daigaku \\ Hironi Makita \\ Hokkaido University: Hokkaido Daigaku \\ Hirokazu Kimura \\ Hokkaido University: Hokkaido Daigaku \\ Kaoruko Shimizu \\ Hokkaido University: Hokkaido Daigaku \\ Satoshi Konno \\ Hokkaido University: Hokkaido Daigaku \\ Masaharu Nishimura \\ Hokkaido University: Hokkaido Daigaku
}

\section{Research}

Keywords: chronic obstructive pulmonary disease, clinically important deterioration, composite measures, exacerbation, mortality

Posted Date: February 11th, 2021

DOl: https://doi.org/10.21203/rs.3.rs-192400/v1

License: (c) (1) This work is licensed under a Creative Commons Attribution 4.0 International License. Read Full License 


\section{Abstract}

Background: Chronic obstructive pulmonary disease (COPD) is a heterogeneous disease with a complex progression of many clinical presentations, and clinically important deterioration (CID) has been proposed in the Western studies as a composite endpoint of disease progression. The aim of this study was to investigate the relationships between 1-year CID and the following long-term clinical outcomes in Japanese patients with COPD who have been reported to have different characteristics compared to the Westerners.

Methods: Among Japanese patients with COPD enrolled in the Hokkaido COPD cohort study, 259 patients who did not drop out within the first year were analyzed in this study. Two definitions of CID were used. Definition 1 comprised $\geq 100 \mathrm{~mL}$ decrease in forced expiratory volume in 1 second $\left(\mathrm{FEV}_{1}\right)$, $\geq 4$-unit increase in St George's Respiratory Questionnaire (SGRQ) score from baseline, or moderate or severe exacerbation. For Definition 2, the thresholds for the FEV ${ }_{1}$ and SGRQ score components were doubled. The presence of CID was evaluated within the first year from enrollment, and analyzed the association of the presence of CID with following 4-year risk of exacerbations and 9-year mortality.

Results: Patients with CID using Definition 1, but not any single CID component, during the first year had a significantly worse mortality compared with those without CID. Patients with CID using Definition 2 showed a similar trend on mortality, and had a shorter exacerbation-free survival compared with those without CID.

Conclusions: Adoption of CID is a beneficial and useful way for the assessment of long-term disease progression and clinical outcomes even in Japanese population with COPD. The definition of CID might be optimized according to the characteristics of COPD population and the observation period for CID.

\section{Background}

Chronic obstructive pulmonary disease (COPD) is a heterogeneous condition with a complex progression of many clinical presentations, which vary in both their presence and severity [1]. The Global Initiative for Chronic Obstructive Lung Disease (GOLD) report describes that it is essential to personalize the assessment and clinical management of COPD, with the treatment goals of reducing the risk of future COPD exacerbations, minimizing disease activity, and preventing disease progression [2]. Quantifying disease activity and progression is a challenge in clinical studies and practice, and a more comprehensive approach to the management of COPD is needed. Therefore, a composite clinically important deterioration (CID) endpoint was developed to measure short-term worsening of disease status, comprising the following: lung function ( $\geq 100 \mathrm{~mL}$ decline in forced expiratory volume in 1 second $\left[\mathrm{FEV}_{1}\right]$ ), health status ( $\geq 4$-unit increase in St George's Respiratory Questionnaire [SGRQ]), and the incidence of moderate or severe exacerbation [3]. The occurrence of one or more of these events was defined as CID. The FEV 1 and SGRQ thresholds were selected as the accepted minimum clinically important difference (MCID) for these outcomes [4, 5]. Several short-term (6-to 12-month) COPD studies 
have adopted this endpoint as a post hoc measure [6, 7], and associations between short-term CID and long-term outcomes have also been reported [8]. However, most of the participants in those studies were from Western countries, and it is still unclear whether this definition of CID is useful in diverse COPD populations.

Japanese patients with COPD have been reported to have different characteristics compared to those from Western countries; they are generally older and thinner, have lower SGRQ scores, and experience fewer exacerbations [9-11]. Therefore, we aimed to investigate whether the presence of any component of the composite CID over a 1-year period was associated with subsequent clinical outcomes (exacerbations and mortality) in Japanese patients with COPD. We used two different thresholds for the $\mathrm{FEV}_{1}$ and SGRQ components to define CID.

\section{Methods}

\section{Study protocol and participants}

The study is based on data from the Hokkaido COPD cohort study, which has previously been described in detail [12-16]. Japanese patients with COPD were enrolled from Hokkaido University Hospital (Sapporo, Japan) and nine affiliated hospitals between May 2003 and May 2005. All were aged over 40 years and were either current or former smokers with a smoking history of at least 10 pack-years. Participants diagnosed with clinical asthma were excluded by respiratory specialists. During the first year of follow-up, we reconfirmed the diagnosis based on the spirometry criteria of the GOLD guidelines [2]. A total of 279 patients with COPD (GOLD 1, 26\%; GOLD 2, 45\%; GOLD 3, 24\%; GOLD 4, 5\%) were followed up in the subsequent years. Until the 5 th year, spirometry before and after bronchodilator inhalation was performed every 6 months. Health-related quality of life assessments with the SGRQ were conducted annually, and information on COPD exacerbations was collected monthly. Moderate exacerbation was defined as a worsening or new onset of either 1 ) two major symptoms (increased dyspnea, change in sputum purulence, or increased sputum volume) or 2) any major symptoms plus any minor symptoms (fever, increased cough, or wheezing) that required a prescription change. Severe exacerbation was defined by hospital admission. After the 5th year, spirometry after bronchodilator inhalation and diffusing capacity testing were conducted annually for those who agreed with the extension of the regular follow-up program until the 10th year. The majority of the participants continued to visit outpatient clinics for appropriate medical care, even if they dropped out of the regular follow-up program. Information on the fatal event was collected as previously described [16]. This study was conducted in accordance with the Declaration of Helsinki and approved by the ethics committee of Hokkaido University School of Medicine (med02-001). All participants provided written informed consent.

\section{Definitions and assessments of CID}

Two definitions of CID were evaluated in this analysis. For Definition 1 (D1), we used the CID previously proposed by Singh et al. [3]. The CID was defined as any one of the following: 1) decrease $\geq 100 \mathrm{~mL}$ from 
baseline in post-bronchodilator $F E V_{1}, 2$ ) increase $\geq 4$ units in SGRQ score from baseline, and 3) incidence of moderate or severe exacerbation. In Definition 2 (D2), the thresholds for the FEV F $_{1}$ and SGRQ components were doubled, as follows: 1 ) decrease $\geq 200 \mathrm{~mL}$ from baseline in post-bronchodilator FEV $\mathrm{F}_{1}$, 2) increase $\geq 8$ units in SGRQ score from baseline; and 3) incidence of moderate or severe exacerbation. In each definition, participants who met at least one CID criteria within the first year of enrollment were classified as the CID1+ (D1) or CID2+ (D2) group, and those who did not, as the CID1- (D1) or CID2- (D2) group.

\section{Statistical analysis}

Differences between the groups were analyzed using Fisher's exact test for categorical variables, Student's $t$ test for continuous parametric variables, and Mann-Whitney $U$ test for continuous nonparametric variables. Exacerbation-free survival and mortality after the visit at 1 year were analyzed using the Kaplan-Meier method with the log-rank test and the multivariate Cox proportional hazards models adjusted for age, sex, and smoking status at enrollment. Statistical significance was defined as $p$ $<0.05$. Statistical analyses were performed using JMP (SAS Institute Inc., Cary, NC, USA) and EZR version 1.54 (Saitama Medical Center, Jichi Medical University, Saitama, Japan), which is a graphical user interface for R software (The R Foundation for Statistical Computing, Vienna, Austria) [17].

\section{Results}

Figure 1 shows the process of this study from registration to CID analysis. Of 279 patients with spirometry-confirmed COPD by the first year, 259 were eligible for this analysis, after the exclusion of 20 patients who dropped out within the first year. Venn diagrams showing the components of the CID based on each definition (D1 and D2) are shown in Figure 2. In D1, 152 (58.7\%) patients were in the CID1+ group and 107 (41.3\%) patients were in the CID1- group. The most common cause of CID in the first year was deterioration in $\mathrm{FEV}_{1}$ (35.5\%), and the least was exacerbation (14.7\%). In D2, 97 (37.5\%) patients were in the CID2+ group and 162 (62.5\%) patients were in the CID2- group. Compared to D1, the positive rates of the three components were similar in $\mathrm{D} 2$ (deterioration in $\mathrm{FEV}_{1}, 12.0 \%$; deterioration in SGRQ, $16.2 \%$; and exacerbation, 14.7\%).

Using D1, the post-bronchodilator $\mathrm{FEV}_{1}$ / forced vital capacity (FVC) was significantly lower in the CID1+ group than in the CID1- group (Table 1). Although there were no associations between the two groups and the development of moderate or severe exacerbations (Figure 3A, 3B), the CID1+ group had worse allcause mortality than the CID1- group ( $p=0.02$, Figure $3 C$ ). Using D2, the post-bronchodilator $\mathrm{FEV}_{1}$ and $\mathrm{FEV}_{1} / \mathrm{FVC}$ were significantly lower in the CID2+ group than in the CID2- group (Table 2). Exacerbation-free survival was significantly shorter in the CID2+ group than in the CID2- group (moderate exacerbation, $p=$ 0.02 , Figure $4 A$; severe exacerbation, $p=0.04$, Figure $4 B$ ). The CID2+ group had worse all-cause mortality than the CID2- group ( $p=0.01$, Figure $4 C$ ). 
The multivariate Cox hazards proportional models showed that among single CID components, the exacerbation component was significantly associated with early onset of moderate exacerbation, and the SGRQ ( $\geq 8$ units) component was associated with early onset of severe exacerbation, whereas other single components were not associated with future exacerbations. In addition, none of the single CID components were associated with all-cause mortality (Table 3). On the other hand, CID using D2, but not $D 1$, was significantly associated with early onset of moderate exacerbation $(p=0.01)$ and tended to relate to severe exacerbation $(p=0.06)$ (Table 3 ). Furthermore, CID using D1 was significantly associated with all-cause mortality $(p=0.047)$, and CID using D2 tended to relate to all-cause mortality $(p=0.052)$.

\section{Discussion}

In this study, we evaluated whether CID status (a composite measure of early deterioration in COPD) assessed during the first year of observation could be used to predict long-term clinical outcomes of Japanese patients with COPD using data from the Hokkaido COPD cohort study. Two definitions of CID (D1 and D2) with different thresholds for FEV ${ }_{1}$ and SGRQ were used. We found that patients who experienced a CID event, but not any single component alone, in the first year had worse all-cause mortality than those who did not experience a CID event under both definitions. In addition, the presence of CID using D2, but not D1, was associated with an earlier onset of exacerbations.

CID is a composite endpoint that was recently introduced in a post-hoc analysis of COPD clinical trials [3, 18-20]. The decline in $\mathrm{FEV}_{1}$ over time has traditionally been an essential marker of disease progression and has been presented as a primary outcome in clinical trials. However, it is widely known that disease progression in COPD is not limited to a decline in $\mathrm{FEV}_{1}$, and that its progression can be monitored in many ways, including by monitoring changes in health status or physical activity over time, as well as the frequency of COPD exacerbations [21]. COPD is a multidimensional disease, and it has been reported that the correlations between changes in $\mathrm{FEV}_{1}$ and SGRQ [22] or exacerbations [23] were not strong. The composite CID endpoint was developed as a new approach to allow reliable monitoring of disease activity and progression using independent components and based on the principle of addressing different aspects of disease progression. Originally, CID consisted of lung function $(\geq 100 \mathrm{~mL}$ decline in $\mathrm{FEV}_{1}$ ), health status ( $\geq 4$-unit increase in SGRQ), and the incidence of moderate or severe exacerbation [3]. The FEV 1 and SGRQ thresholds were selected from the established MCID $[4,5]$.

To evaluate the composite CID endpoint, it is important to know whether the composite CID is more useful than a single CID component as an outcome and whether it has prognostic ability in diverse COPD populations [24]. A post-hoc analysis of the 3-year TORCH and ECLIPSE studies showed that patients with CID had an increased risk of all-cause mortality compared with patients without CID after a CID assessment at 6 and 12 months, respectively [8]. It was also reported that patients with CID within the first 6 months of the UPLIFT study had worse outcomes for the remaining 42 months of the study [25]. However, the usefulness of CID in Japanese patients with COPD has not yet been clarified. In this study, we found that the presence of composite CID over a 1-year period was associated with subsequent 
exacerbations and better all-cause mortality than any single CID component (Table 3). This suggests that the composite CID endpoint would also be useful and beneficial among Japanese patients with COPD.

Recent reports on CID have explored other definitions in addition to the three-component CID definition as described above, including the COPD Assessment Test score [26] and the Transition Dyspnea Index [18]. However, there have been no studies that have used different thresholds for each CID component. When we adopted the original definition for each component of CID (i.e., D1), the positive rates of the three components were not uniform (Figure 2A). On the other hand, when we used doubled thresholds for the $\mathrm{FEV}_{1}$ and SGRQ score components (D2), the positive rates of the three components were similar (Figure 2B). In addition, CID using D2 was associated with a higher risk of exacerbations than CID using D1. We evaluated the CID over a 1-year period, which is longer than the TORCH [8] and UPLIFT [25] studies, in which CID was evaluated for 6 months. In addition, previous reports suggested that Japanese patients with COPD have less frequent exacerbations than patients in other countries [11]. Data from the UPLIFT study also suggested that Japanese patients have a lower baseline SGRQ than patients in the rest of the world [9]. Therefore, the definition of CID might be optimized according to the characteristics of the COPD population and the period of evaluation in order to properly assess clinical outcomes using CID.

The use of CID is a useful approach for the assessment of long-term disease progression and clinical outcomes in patients with COPD, and thus potentially applicable for future large-scale randomized clinical trials. However, it remains uncertain whether the use of CID contributes to improved care of individual patients with COPD in practical clinical settings. It is well known that SGRQ scores reported by individual patients are sometimes unacceptably variable over time due to factors that may not necessarily be related to COPD itself. We have recently reported how variable pulmonary function parameters such as $\mathrm{FEV}_{1}$ are even among three acceptable trials [27]. The difference between the maximal and minimal FEV 1 values among the acceptable trials was more than the MCID for $\mathrm{FEV}_{1}(100$ $\mathrm{mL}$ ) in as many as $14 \%$ of the participants, regardless of the GOLD stages of airflow limitation.

This study has several limitations. First, the sample size was not as large as those in previous large-scale clinical studies. However, this study was carefully designed with high quality, the dropout rate was low, and the accurate mortality data were obtained for as long as 10 years. Second, the SGRQ was only assessed once a year, so it was not possible to assess the CID in a shorter period of time. However, the SGRQ is complex and difficult to assess frequently in clinical practice, and our results suggest that the assessment of CID on an annual basis may also play an important role in predicting subsequent longterm clinical outcomes. Third, the thresholds for each component of the CID have not been validated. The purpose of this study was not to find the most useful cutoff value for CID, but to examine the usefulness of CID in Japanese patients with COPD. Future large-scale studies may be needed to explore more appropriate thresholds for each component of CID.

\section{Conclusions}


One-year deterioration assessed using a composite CID endpoint was associated with poor long-term clinical outcomes in Japanese patients with COPD. It was also suggested that the definition of CID should be optimized according to the characteristics of the COPD population and the period of evaluation. This concept of evaluating short-term changes across multiple endpoints may help identify patients at high risk for worsening of COPD earlier. Further research may be needed on the relationship between CID thresholds and long-term outcomes for future clinical trials.

\section{Abbreviations}

COPD, chronic obstructive pulmonary disease

GOLD, Global Initiative for Chronic Obstructive Lung Disease

CID, clinically important deterioration

$\mathrm{FEV}_{1}$, forced expiratory volume in 1 second

SGRQ, St. George's Respiratory Questionnaire

MCID, minimum clinically important difference

D1, Definition 1

D2, Definition 2

FVC, forced vital capacity

\section{Declarations}

Ethics approval and consent to participate

This study was approved by the ethics committees of all hospitals, and all participants provided written informed consent. This study was approved by the ethics committee of Hokkaido University School of Medicine (med02-001).

\section{Consent for publication}

Not applicable.

\section{Availability of data and materials}

The datasets used and/or analyzed during the current study are available from the corresponding author on reasonable request. 
MS, HM, KS, SK, and MN have received grants from Boehringer-Ingelheim and Pfizer during the conduct of the study. MS has received grants from Boehringer-Ingelheim, Novartis, and AstraZeneca outside the submitted work. MN has received personal fees from Boehringer-Ingelheim, Novartis, and AstraZeneca outside the submitted work. AY and HK declare that they have no conflicts of interest in this work.

\section{Funding}

The Hokkaido COPD cohort study was supported by a scientific research grant from the Ministry of Education, Science, Culture and Sports of Japan; a grant to the Respiratory Failure Research Group from the Ministry of Health, Labor and Welfare, Japan; and from Boehringer-Ingelheim and Pfizer.

\section{Authors' contributions}

All authors made substantial contributions to conception and design, acquisition of data, or analysis and interpretation of data; took part in drafting the article or revising it critically for important intellectual content; gave final approval of the version to be published; and agree to be accountable for all aspects of the work.

\section{Acknowledgements}

The authors would like to thank all of the Hokkaido COPD cohort study investigators for patient recruitment and follow-up, as well as Hideka Ashikaga, Ayako Kondo, and Yuko Takagi of the Central Office of the Hokkaido COPD cohort study (Sapporo, Japan) and the staff of Exam Co., Ltd. (Sapporo, Japan) for data management.

\section{References}

1. Agusti A, Calverley PM, Celli B, Coxson HO, Edwards LD, Lomas DA, et al. Characterisation of COPD heterogeneity in the ECLIPSE cohort. Respir Res. 2010;11(1):122.

2. Global Initiative for Chronic Obstructive Lung Disease. Global strategy for the diagnosis, management, and prevention of chronic obstructive pulmonary disease. Updated 2021. https://goldcopd.org. Accessed 7 Jan 2021.

3. Singh D, Maleki-Yazdi MR, Tombs L, Iqbal A, Fahy WA, Naya I. Prevention of clinically important deteriorations in COPD with umeclidinium/vilanterol. Int J Chron Obstruct Pulmon Dis. 2016;11:141324.

4. Donohue JF. Minimal clinically important differences in COPD lung function. COPD. 2005;2(1):11124.

5. Jones PW. St. George's Respiratory Questionnaire: MCID. COPD. 2005;2(1):75-9.

6. Bafadhel M, Singh D, Jenkins C, Peterson S, Bengtsson T, Wessman P, et al. Reduced risk of clinically important deteriorations by ICS in COPD is eosinophil dependent: a pooled post-hoc analysis. Respir Res. 2020;21(1):17. 
7. Rabe KF, Chalmers JD, Miravitlles M, Kocks JWH, Tsiligianni I, de la Hoz A, et al.

Tiotropium/Olodaterol delays clinically important deterioration compared with tiotropium monotherapy in patients with early COPD: a post hoc analysis of the TONADO(®) trials. Adv Ther. 2020.

8. Naya IP, Tombs L, Muellerova H, Compton C, Jones PW. Long-term outcomes following first shortterm clinically important deterioration in COPD. Respir Res. 2018;19(1):222.

9. Fukuchi Y, Fernandez L, Kuo HP, Mahayiddin A, Celli B, Decramer M, et al. Efficacy of tiotropium in COPD patients from Asia: a subgroup analysis from the UPLIFT trial. Respirology. 2011;16(5):825-35.

10. Ichinose M, Taniguchi H, Takizawa A, Grönke L, Loaiza L, Voß F, et al. The efficacy and safety of combined tiotropium and olodaterol via the Respimat $(\circledR)$ inhaler in patients with COPD: results from the Japanese sub-population of the Tonado $\left({ }^{\circledR}\right)$ studies. Int J Chron Obstruct Pulmon Dis. 2016;11:2017-27.

11. Ishii T, Nishimura $M$, Akimoto $A$, James $M H$, Jones P. Understanding low COPD exacerbation rates in Japan: a review and comparison with other countries. Int $\mathrm{J}$ Chron Obstruct Pulmon Dis. 2018;13:3459-71.

12. Makita $H$, Nasuhara $Y$, Nagai $K$, Ito $Y$, Hasegawa $M$, Betsuyaku T, et al. Characterisation of phenotypes based on severity of emphysema in chronic obstructive pulmonary disease. Thorax. 2007;62(11):932-7.

13. Nishimura M, Makita H, Nagai $K$, Konno S, Nasuhara $Y$, Hasegawa $M$, et al. Annual change in pulmonary function and clinical phenotype in chronic obstructive pulmonary disease. Am J Respir Crit Care Med. 2012;185(1):44-52.

14. Suzuki M, Makita H, Ito YM, Nagai K, Konno S, Nishimura M. Clinical features and determinants of COPD exacerbation in the Hokkaido COPD cohort study. Eur Respir J. 2014;43(5):1289-97.

15. Suzuki M, Makita H, Konno S, Shimizu K, Kimura H, Kimura H, et al. Asthma-like features and clinical course of chronic obstructive pulmonary disease. An analysis from the Hokkaido COPD cohort study. Am J Respir Crit Care Med. 2016;194(11):1358-65.

16. Makita H, Suzuki M, Konno S, Shimizu K, Nasuhara Y, Nagai K, et al. Unique mortality profile in Japanese patients with COPD: an analysis from the Hokkaido COPD cohort study. Int J Chron Obstruct Pulmon Dis. 2020;15:2081-90.

17. Kanda Y. Investigation of the freely available easy-to-use software 'EZR' for medical statistics. Bone Marrow Transplant. 2013;48(3):452-8.

18. Anzueto AR, Vogelmeier CF, Kostikas K, Mezzi K, Fucile S, Bader G, et al. The effect of indacaterol/glycopyrronium versus tiotropium or salmeterol/fluticasone on the prevention of clinically important deterioration in COPD. Int J Chron Obstruct Pulmon Dis. 2017;12:1325-37.

19. Greulich T, Kostikas K, Gaga M, Aalamian-Mattheis M, Lossi NS, Patalano F, et al. Indacaterol/glycopyrronium reduces the risk of clinically important deterioration after direct switch from baseline therapies in patients with moderate COPD: a post hoc analysis of the CRYSTAL study. Int J Chron Obstruct Pulmon Dis. 2018;13:1229-37. 
20. Singh D, D'Urzo AD, Chuecos F, Muñoz A, Garcia Gil E. Reduction in clinically important deterioration in chronic obstructive pulmonary disease with aclidinium/formoterol. Respir Res. 2017;18(1):106.

21. Halpin DM, Tashkin DP. Defining disease modification in chronic obstructive pulmonary disease. COPD. 2009;6(3):211-25.

22. Nagai K, Makita H, Suzuki M, Shimizu K, Konno S, Ito YM, et al. Differential changes in quality of life components over 5 years in chronic obstructive pulmonary disease patients. Int $\mathrm{J}$ Chron Obstruct Pulmon Dis. 2015;10:745-57.

23. Celli BR, Thomas NE, Anderson JA, Ferguson GT, Jenkins CR, Jones PW, et al. Effect of pharmacotherapy on rate of decline of lung function in chronic obstructive pulmonary disease: results from the TORCH study. Am J Respir Crit Care Med. 2008;178(4):332-8.

24. Singh D, Criner GJ, Naya I, Jones PW, Tombs L, Lipson DA, et al. Measuring disease activity in COPD: is clinically important deterioration the answer? Respir Res. 2020;21(1):134.

25. Rabe KF, Halpin DMG, Han MK, Miravitlles M, Singh D, Grönke L, et al. Composite endpoints in COPD: clinically important deterioration in the UPLIFT trial. Respir Res. 2020;21(1):177.

26. Naya I, Compton C, Ismaila AS, Birk R, Brealey N, Tabberer M, et al. Preventing clinically important deterioration with single-inhaler triple therapy in COPD. ERJ Open Res. 2018;4(4).

27 Yamamoto M, Konno S, Makita H, Nitta K, Shimizu K, Suzuki M, Nishida M, Sugita J, Teshima T, Nishimura M. Factors for the variability of three acceptable maximal expiratory flow-volume curves in chronic obstructive pulmonary disease. Int J Chron Obstruct Pulmon Dis. 2021 in press.

\section{Tables}


Table1. Patient demographics and baseline characteristics, based on CID using D1

$\begin{array}{llll}\text { All patients } & \text { CID1+ group } & \text { CID1-group } & \text { P-value } \\ (n=259) & (n=152) & (n=107) & \end{array}$

\section{Demographics}

\begin{tabular}{|c|c|c|c|c|}
\hline Age, years & $69.6 \pm 7.8$ & $69.8 \pm 7.5$ & $69.4 \pm 8.2$ & 0.74 \\
\hline Female, N (\%) & $15(5.8 \%)$ & $7(4.6 \%)$ & $8(7.5 \%)$ & 0.42 \\
\hline Body mass index, $\mathrm{kg} / \mathrm{m}^{2}$ & $22.2 \pm 3.2$ & $22.1 \pm 3.3$ & $22.5 \pm 3.2$ & 0.30 \\
\hline Current smoker, $\mathrm{N}(\%)$ & $73(28.2 \%)$ & $39(25.7 \%)$ & $34(31.8 \%)$ & 0.33 \\
\hline Pack-years & $56.0(43.0-78.0)$ & $56.0(43.0-75.8)$ & $57.0(43.0-79.5)$ & 0.66 \\
\hline \multicolumn{5}{|l|}{ Pulmonary function test } \\
\hline Post-BD FEV $1, \mathrm{~L}$ & $1.7 \pm 0.7$ & $1.7 \pm 0.7$ & $1.8 \pm 0.7$ & 0.19 \\
\hline Post-BD FEV $1, \%$ predicted & $64.5 \pm 21.9$ & $62.3 \pm 21.8$ & $67.8 \pm 21.6$ & 0.05 \\
\hline Post-BD FEV $_{1} / F V C, \%$ & $51.1 \pm 12.5$ & $49.6 \pm 12.6$ & $53.2 \pm 12.1$ & 0.02 \\
\hline DLco, \% predicted & $78.1 \pm 25.0$ & $76.2 \pm 24.8$ & $80.7 \pm 25.2$ & 0.16 \\
\hline Kco, \% predicted & $63.8 \pm 24.3$ & $62.6 \pm 24.7$ & $65.4 \pm 23.7$ & 0.37 \\
\hline \multicolumn{5}{|l|}{ Patient-reported outcomes } \\
\hline Chronic bronchitis, N (\%) & $29(11.2 \%)$ & $16(10.5 \%)$ & $13(12.2 \%)$ & 0.69 \\
\hline mMRC dyspnea scale $\geq 2, N(\%)$ & $137(52.9 \%)$ & $84(55.3 \%)$ & $53(49.5 \%)$ & 0.38 \\
\hline SGRQ total score & $31.8 \pm 17.4$ & $32.4 \pm 17.4$ & $31.1 \pm 17.4$ & 0.57 \\
\hline CT emphysema score & $1.2(0.7-2.0)$ & $1.2(0.8-2.2)$ & $1.1(0.6-2.0)$ & 0.30 \\
\hline \multicolumn{5}{|l|}{ Comorbidities } \\
\hline Any cardiovascular disease & $58(22.4 \%)$ & $33(21.7 \%)$ & $25(23.4 \%)$ & 0.76 \\
\hline Ischemic heart disease & $18(7.0 \%)$ & $10(6.6 \%)$ & $8(7.5 \%)$ & 0.81 \\
\hline Diabetes & $12(4.6 \%)$ & $4(2.6 \%)$ & $8(7.5 \%)$ & 0.08 \\
\hline
\end{tabular}

CID, clinically important deterioration; D1, Definition 1; post-BD, post-bronchodilator; FEV 1 , forced expiratory volume in 1 second; FVC, forced vital capacity; DLco, carbon monoxide diffusion capacity; Kco, carbon monoxide transfer coefficient; mMRC, modified Medical Research Council; SGRQ, St. George's Respiratory Questionnaire; CT, computed tomography. 
Data are shown as the mean \pm standard deviation (SD), median (interquartile range), or number (\%).

P-values were obtained using the Fisher's exact test, Student's t-test, or the Mann-Whitney U test, as appropriate. 
Table2. Patient demographics and baseline characteristics, based on CID using D2

$\begin{array}{lll}\text { CID2+ group } & \text { CID2- group } & \text { P-value } \\ (n=97) & (n=162)\end{array}$

\section{Demographics}

Age, years

$70.1 \pm 7.2$

$69.4 \pm 8.1$

0.45

Female, $\mathrm{N}(\%)$

$4(4.1 \%)$

$11(6.8 \%)$

0.43

Body mass index, $\mathrm{kg} / \mathrm{m}^{2}$

$22.0 \pm 3.2$

$22.4 \pm 3.3$

0.33

Current smoker, N (\%)

$21(21.7 \%)$

$52(32.1 \%)$

0.09

Pack-years

$55.0(42.0-73.5)$

$56.6(43.5-82.0)$

0.33

\section{Pulmonary function test}

Post-BD FEV 1 , L

$1.6 \pm 0.6$

$1.8 \pm 0.7$

0.01

Post-BD FEV ${ }_{1}, \%$ predicted

$59.2 \pm 20.9$

$67.8 \pm 21.9$

0.002

Post-BD FEV ${ }_{1} /$ FVC, $\%$

$48.2 \pm 12.7$

$52.8 \pm 12.2$

0.003

DLco, \% predicted

$77.3 \pm 24.8$

$78.5 \pm 25.2$

0.70

Kco, \% predicted

$63.3 \pm 24.6$

$64.0 \pm 24.2$

0.82

\section{Patient-reported outcomes}

Chronic bronchitis, N (\%)

$13(13.4 \%)$

$16(9.9 \%)$

0.42

mMRC dyspnea scale $\geq 2, N(\%)$

SGRQ total score

$55(56.7 \%)$

$82(50.6 \%)$

0.37

$33.8 \pm 17.3$

$30.7 \pm 17.3$

0.16

CT emphysema score

$1.2(0.7-2.0)$

$1.2(0.7-2.2)$

0.97

\section{Comorbidities}

Any cardiovascular disease

Ischemic heart disease

Diabetes

\begin{tabular}{lll}
$23(23.7 \%)$ & $35(21.6 \%)$ & 0.76 \\
\hline $6(6.2 \%)$ & $12(7.4 \%)$ & 0.80 \\
$3(3.1 \%)$ & $9(5.6 \%)$ & 0.54
\end{tabular}


CID, clinically important deterioration; D2, Definition 2; post-BD, post-bronchodilator; FEV 1 , forced expiratory volume in 1 second; FVC, forced vital capacity; DLco, carbon monoxide diffusion capacity; Kco, carbon monoxide transfer coefficient; mMRC, modified Medical Research Council; SGRQ, St. George's Respiratory Questionnaire; CT, computed tomography.

Data are shown as the mean \pm standard deviation (SD), median (interquartile range), or number (\%).

P-values were obtained using the Fisher's exact test, Student's t-test, or the Mann-Whitney U test, as appropriate.

Table3. Hazard ratios of single CID events and composite CID events for CID+ patients versus CIDpatients

\begin{tabular}{|c|c|c|c|c|c|c|}
\hline \multirow[b]{2}{*}{ Risk factor } & \multicolumn{2}{|c|}{ Moderate exacerbation } & \multicolumn{2}{|c|}{ Severe exacerbation } & \multicolumn{2}{|c|}{ All-cause mortality } \\
\hline & $\begin{array}{l}\text { Hazard ratio } \\
(95 \% \mathrm{Cl})\end{array}$ & $\begin{array}{l}\mathrm{P} \text { - } \\
\text { value }\end{array}$ & $\begin{array}{l}\text { Hazard ratio } \\
(95 \% \mathrm{Cl})\end{array}$ & $\begin{array}{l}\mathrm{P}- \\
\text { value }\end{array}$ & $\begin{array}{l}\text { Hazard ratio } \\
(95 \% \mathrm{Cl})\end{array}$ & $\begin{array}{l}\mathrm{P} \text { - } \\
\text { value }\end{array}$ \\
\hline \multicolumn{7}{|l|}{$\begin{array}{l}\text { Single CID } \\
\text { components }\end{array}$} \\
\hline $\begin{array}{l}\mathrm{FEV}_{1} \text { decrease }(\geq 100 \\
\mathrm{mL})\end{array}$ & $\begin{array}{l}0.78(0.47- \\
1.26)\end{array}$ & 0.32 & $\begin{array}{l}0.64(0.25- \\
1.44)\end{array}$ & 0.29 & $\begin{array}{l}1.28(0.84- \\
1.91)\end{array}$ & 0.25 \\
\hline $\begin{array}{l}\mathrm{FEV}_{1} \text { decrease }(\geq 200 \\
\mathrm{mL})\end{array}$ & $\begin{array}{l}0.59(0.23- \\
1.26)\end{array}$ & 0.19 & $\begin{array}{l}0.98(0.23- \\
2.81)\end{array}$ & 0.97 & $\begin{array}{l}1.39(0.74- \\
2.42)\end{array}$ & 0.29 \\
\hline $\begin{array}{l}\text { SGRQ increase ( } \geq 4 \\
\text { units) }\end{array}$ & $\begin{array}{l}1.01(0.61- \\
1.62)\end{array}$ & 0.97 & $\begin{array}{l}1.78(0.82- \\
3.74)\end{array}$ & 0.14 & $\begin{array}{l}1.33(0.88- \\
1.99)\end{array}$ & 0.17 \\
\hline $\begin{array}{l}\text { SGRQ increase ( } \geq 8 \\
\text { units) }\end{array}$ & $\begin{array}{l}1.28(0.70- \\
2.19)\end{array}$ & 0.41 & $\begin{array}{l}2.88(1.28- \\
6.14)\end{array}$ & 0.01 & $\begin{array}{l}1.39(0.86- \\
2.18)\end{array}$ & 0.17 \\
\hline Exacerbation & $\begin{array}{l}2.87(1.64- \\
4.83)\end{array}$ & 0.0004 & $\begin{array}{l}1.09(0.32- \\
2.88)\end{array}$ & 0.87 & $\begin{array}{l}1.17(0.65- \\
1.97)\end{array}$ & 0.59 \\
\hline \multicolumn{7}{|l|}{ Composite CID } \\
\hline CID using D1 & $\begin{array}{l}1.44(0.90- \\
2.34)\end{array}$ & 0.13 & $\begin{array}{l}1.21(0.57- \\
2.73)\end{array}$ & 0.63 & $\begin{array}{l}1.52(1.006- \\
2.34)\end{array}$ & 0.047 \\
\hline CID using D2 & $\begin{array}{l}1.78(1.12- \\
2.81)\end{array}$ & 0.01 & $\begin{array}{l}2.09(0.98- \\
4.53)\end{array}$ & 0.06 & $\begin{array}{l}1.48(0.997- \\
2.20)\end{array}$ & 0.052 \\
\hline
\end{tabular}

$\mathrm{CID}$, clinically important deterioration; $\mathrm{Cl}$, confidence interval; $\mathrm{FEV}_{1}$, forced expiratory volume in 1 second; SGRQ, St. George's Respiratory Questionnaire; D1, Definition 1; D2, Definition 2. 
The hazard ratio was derived from the multivariate Cox proportional hazards models adjusted for age, sex, and smoking status.

\section{Figures}


Figure 1

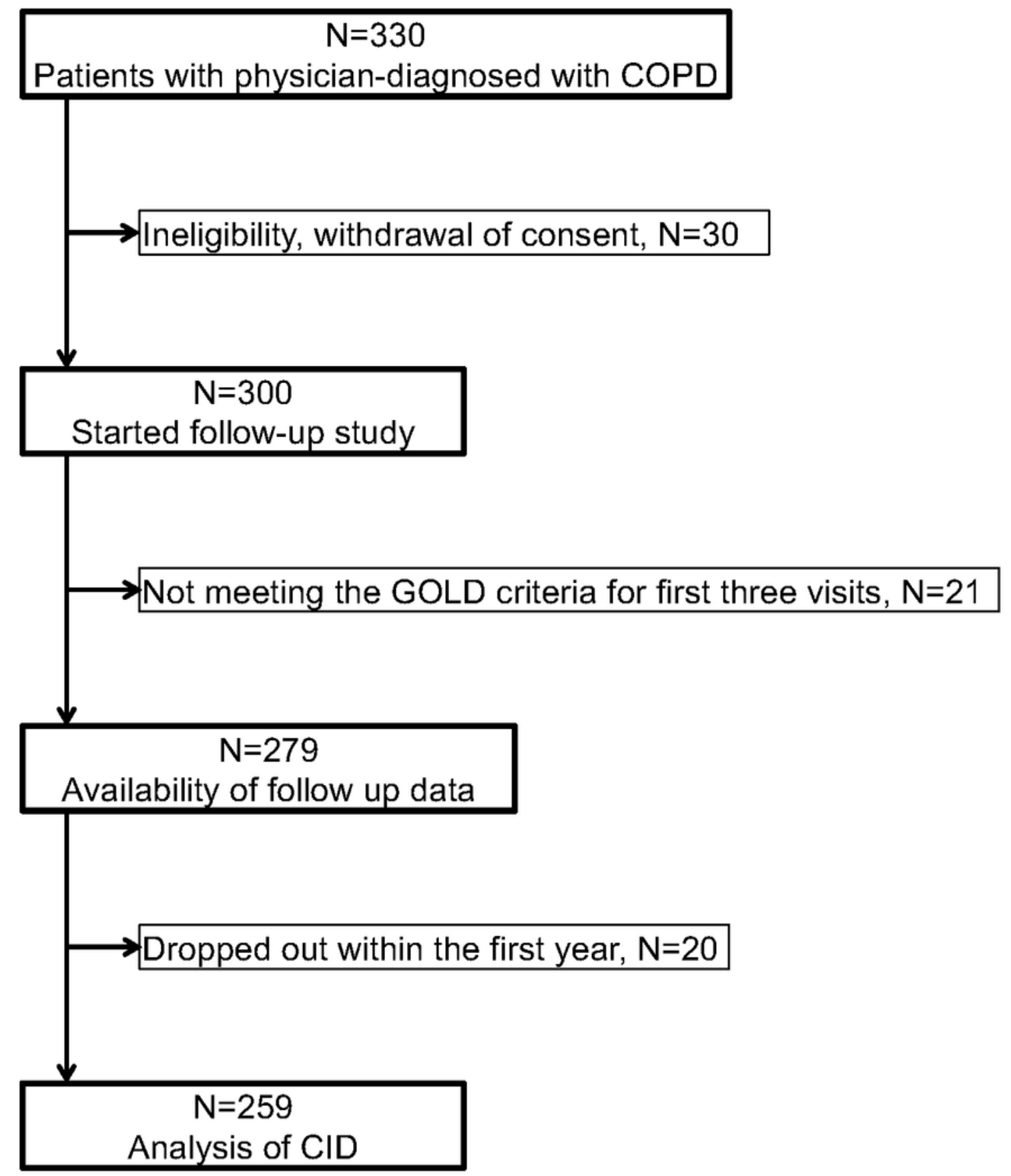

Figure 1

Flow-chart showing the study process 
Figure 2

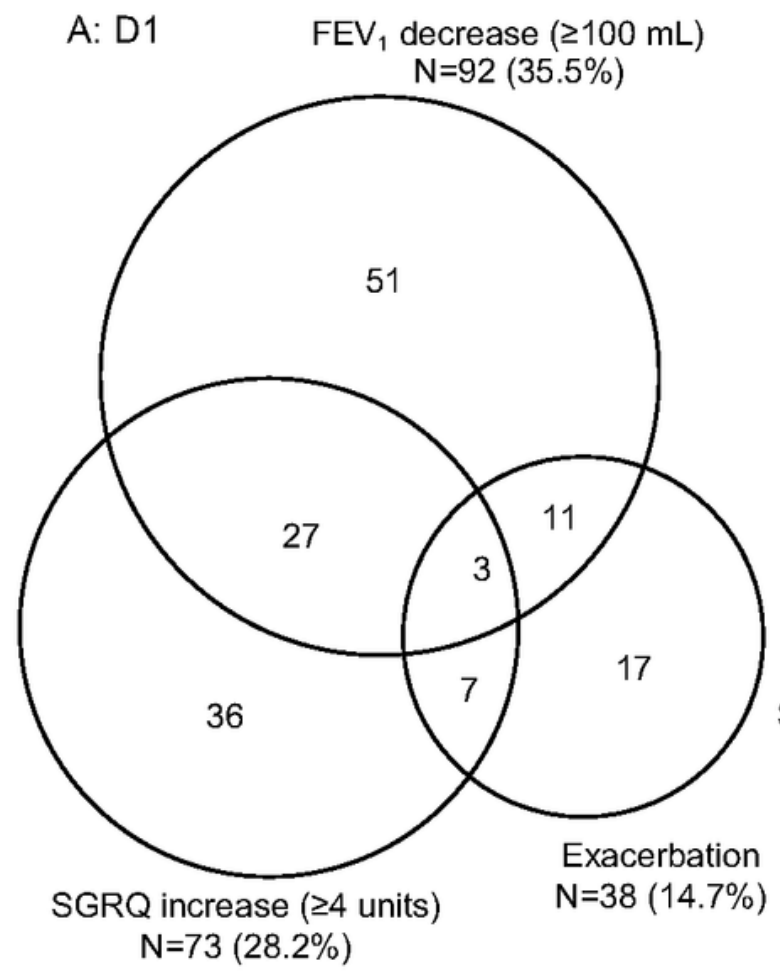

$152(58.7 \%)$ patients : CID1+ group $107(41.3 \%)$ patients : CID1- group
B: D2

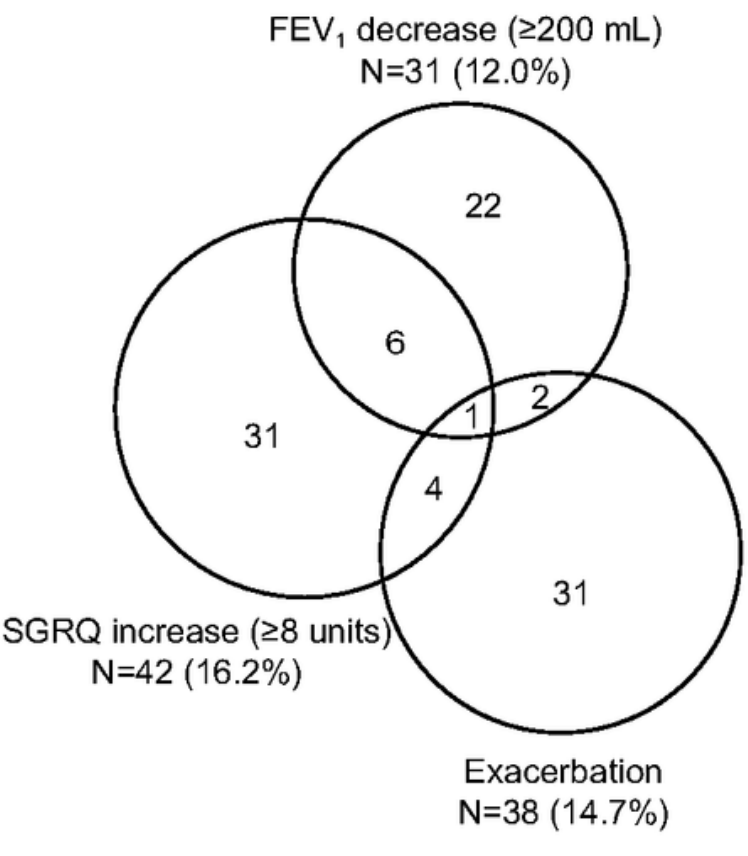

$97(37.5 \%)$ patients : CID2+ group $162(62.5 \%)$ patients : CID2- group

\section{Figure 2}

Individual components of the CID in the first year based on (A) D1 and (B) D2. 


\section{Figure 3}

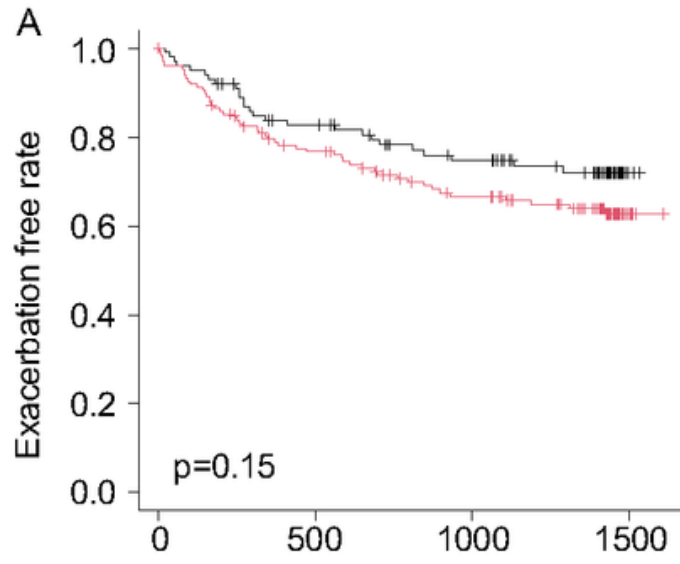

Days to first event after the first year (moderate exacerbation)

C

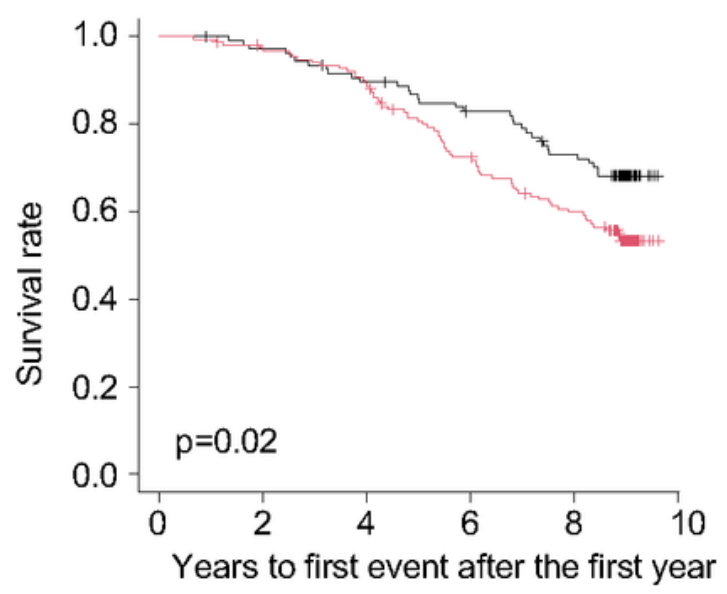

B

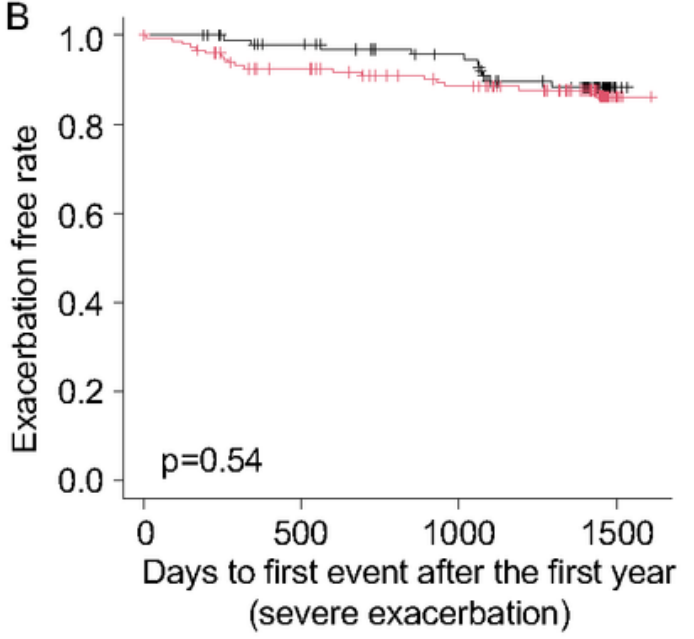

- CID1- group
$-\quad$ CID1+ group

(CID using D1)

\section{Figure 3}

Kaplan-Meier curves according to CID using D1 (A) Moderate exacerbations. (B) Severe exacerbations. (C) All-cause mortality. 
Figure 4

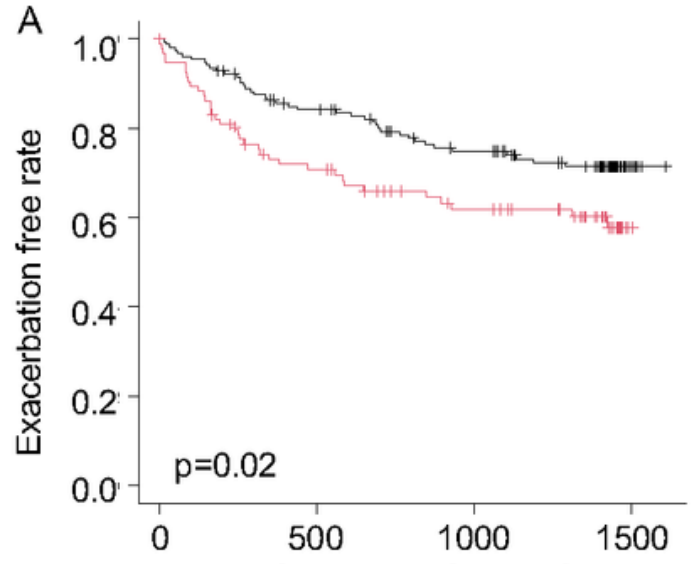

Days to first event after the first year (moderate exacerbation)

C

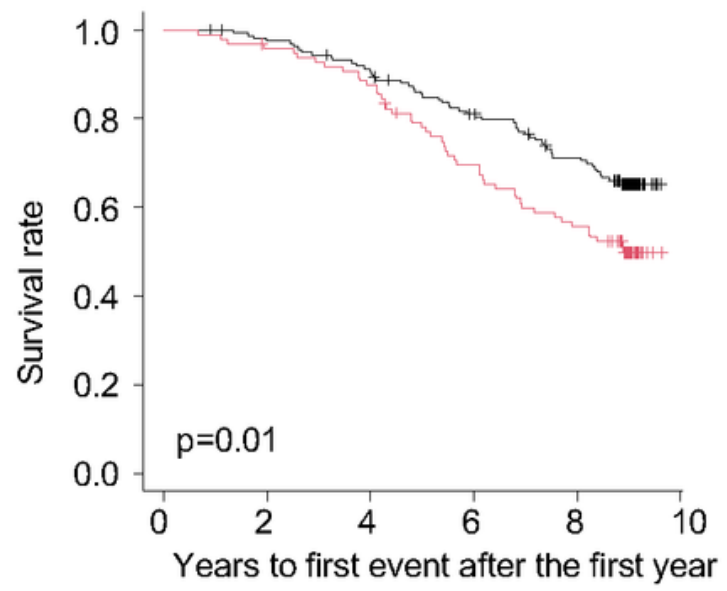

B

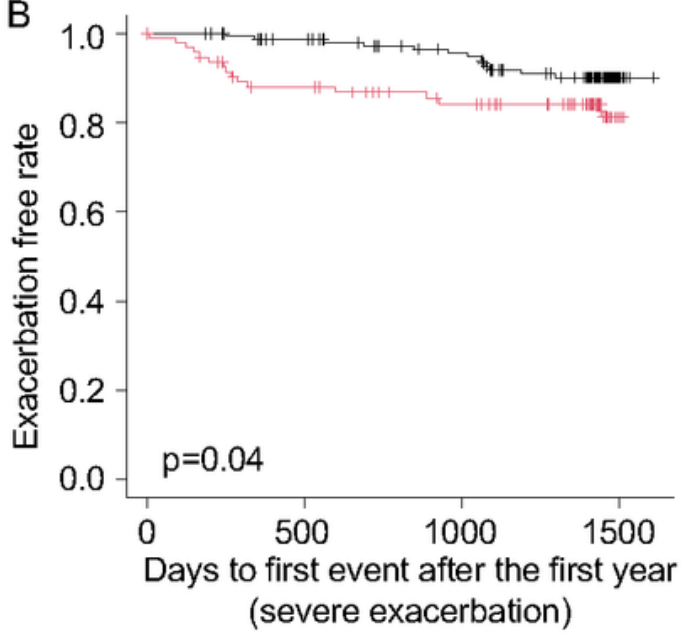

$\begin{array}{cc}- & \text { CID2- group } \\ - & \text { CID2+ group } \\ \text { (CID using D2) }\end{array}$

\section{Figure 4}

Kaplan-Meier curves according to CID using D2 (A) Moderate exacerbations. (B) Severe exacerbations. (C) All-cause mortality. 